\title{
Traumatic diaphragmatic rupture, a diagnostic dilemma in the presence of eventration: a case report
} Reyaz Ahmad Lone ${ }^{1}{ }^{*}$, Mukand Lal Sharma ${ }^{1}$, Mahmood Wani ${ }^{1}$, Shiraz Rather ${ }^{1}$, Abdul Gani Ahangar ${ }^{1}$, Fouzia Rasool ${ }^{1,2}$, Mohd Akbar Bhat ${ }^{1}$, Abdul Majid Dar ${ }^{1}$, Guhlam Nabi Lone ${ }^{1}$, Shyam Singh ${ }^{1}$, Ishtiyaq Mir ${ }^{1}$, Shabir Shah ${ }^{1}$, Mubashir Shah ${ }^{1}$ and Mohd Lateef Wani ${ }^{1}$

\author{
Addresses: ${ }^{1}$ Department of Cardiothoracic and Vascular Surgery, Sheri Kashmir Institute of Medical Sciences, Soura, Srinagar, Kashmir, \\ 190011, India \\ ${ }^{2}$ Department of General Surgery, Shri Maharaja Hari Singh Medical College, Karanagr, MS, Srinagar, Kashmir, 190011, India \\ Email: RAL* - drreyazlone@gmail.com; MLS - mukan20@yahoo.co.in; MW - mav80@yahoo.co.in; SR - shirazar@rdiff.mail.com; \\ AGA - ahangerag@gmail.com; FR - drfouziarl@gmail.com; MAB - drmakbarbhat@yahoo.co.uk; AMD - bmajeed786@gmail.com; \\ GNL - gn_lone@yahoo.co.in; SSi - drshyamsingh@rediffmail.com; IM - ishtyak_mir@rediffmail.com; SSh - drshahshabir@rediffmail.com; \\ MS - mashah@rediffmail.com; MLW - lateef@rediffmail.com \\ * Corresponding author
}

Received: 18 March 2009 Accepted: 10 June 2009 Published: 3 September 2009

Cases Journal 2009, 2:6615 doi: 10.4076/1757-1626-2-6615

This article is available from: http://casesjournal.com/casesjournal/article/view/66/5

(c) 2009 Lone et al.; licensee Cases Network Ltd.

This is an Open Access article distributed under the terms of the Creative Commons Attribution License (http://creativecommons.org/licenses/by/3.0), which permits unrestricted use, distribution, and reproduction in any medium, provided the original work is properly cited.

\begin{abstract}
Eventration of the diaphragm is the condition where the muscle is permanently elevated, but retains its continuity and attachments to the costal margins. Traumatic diaphragmatic rupture is a recognized consequence of high velocity blunt trauma to the abdomen usually a result of motor vehicle accident. Multi-slice CT and Magnetic Resonance Imaging in the pre-operative evaluation of trauma patients, diaphragmatic rupture can be still overlooked if not evaluated with the fair degree of clinical suspicion, more so if it is associated with an eventration of diaphragm - as was in our case.
\end{abstract}

\section{Introduction}

Traumatic diaphragmatic rupture (TDR) is a recognized consequence of high velocity blunt trauma to the abdomen usually a result of motor vehicle accident (MVA). It has been reported in upto $5 \%$ of thoracoabdominal trauma patients. Early recognition of TDR is of utmost importance. Despite the development and availability of new gadgets including multi-slice CT and Magnetic Resonance Imaging in the pre-operative evaluation of trauma patients, diaphragmatic rupture can be still overlooked if not evaluated with the fair degree of clinical suspicion, more so if it is associated with an eventration of diaphragm - as was in our case.

\section{Case presentation}

A 4-year-old, male child of Indian origin was referred to the emergency department of Sheri Kashmir Institute of Medical Sciences, the tertiary care institute of the state with a history of being in a road traffic accident causing chest and abdominal trauma. At the peripheral centre where the 
child was first seen resuscitation had been started and a chest tube had been placed on the right side and $200 \mathrm{ml}$ of blood had been drained. The child was referred because of history of eventration of the diaphragm on the same side. At admission the child was semiconscious, pale, had features of respiratory distress with a rate of 54 breaths per minute and was in shock with no palpable peripheral pulse and an unrecordable BP. Immediately the child was intubated and further lines were set up to enable resuscitation. Secondary survey revealed bruise over the right chest, decreased air entry on the right side, central placed mediastinal structures and normal heart sounds. Rest of his examination was normal.

After resuscitation the patient was taken for CT scan of abdomen and chest. CT showed free fluid in the abdominal cavity, a right sided retroperitoneal haematoma, a right lung contusion, a right haemothorax and the presence of right sided chest tube (Figure 1). The

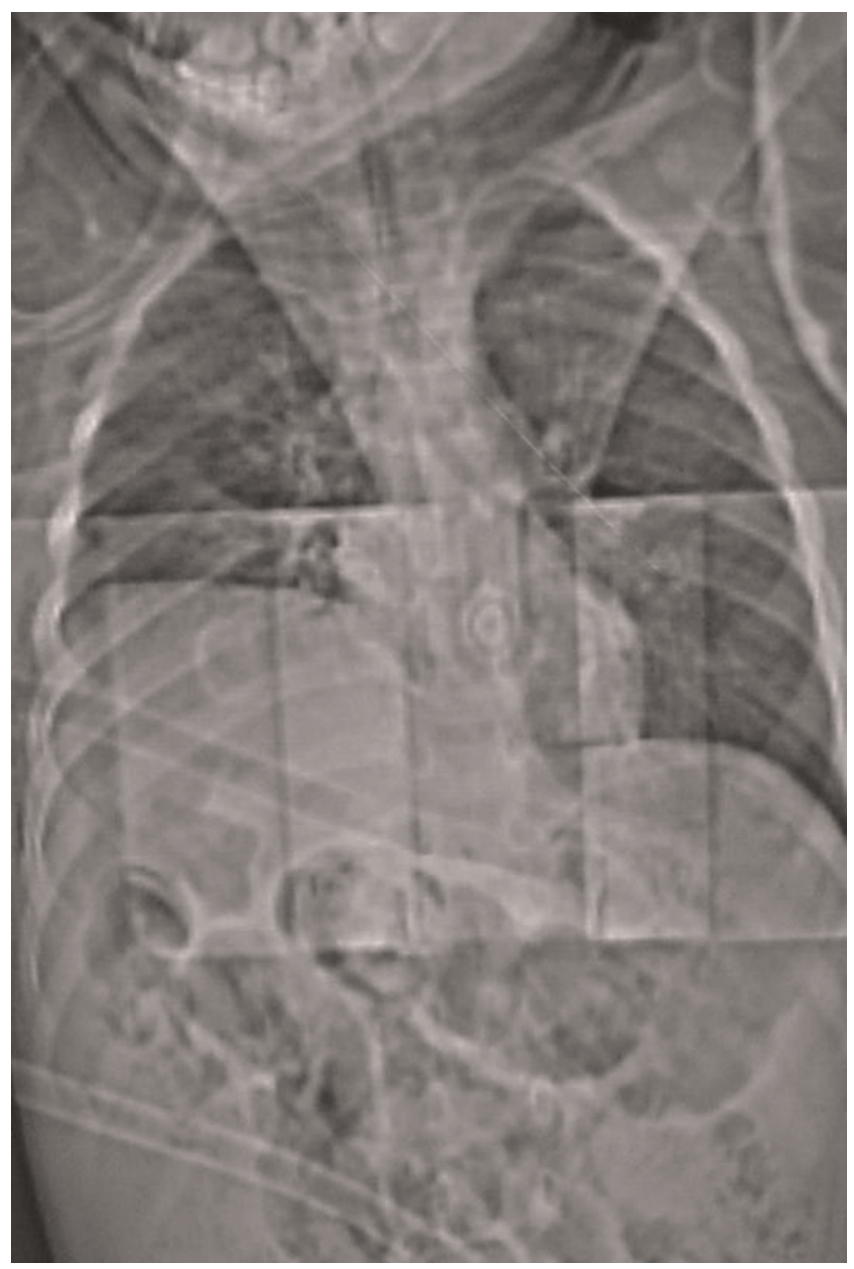

Figure I. X-ray chest showing elevated right dome of diaphragm. diaphragm was noted at higher level but it could not be determined whether there was any injury to it (Figure 2). Subsequently the patient was subjected to exploratory laparotomy because a TDR could not be ruled out by imaging. At surgery note was made of complete rupture of the right dome of the diaphragm with almost the whole liver in the right chest. The retroperitoneal haematoma was found to be non-expanding and about $300 \mathrm{ml}$ of blood was found in the abdominal cavity. The right lower lobe of lung was contused, the pericardium was torn on the right side and its edges were bleeding. The pericardial edges were cauterized, the liver returned to the abdominal cavity and the diaphragm repaired with $2 / 0$ prolene interrupted mattress sutures.

The patient was electively ventilated for 24 hours after which he was extubated and shifted to ward. On the second postoperative the patient started draining chyle (400-500 $\mathrm{ml} /$ day) from the right chest tube, confirmed by biochemical analysis. His drainage subsequently decreased by the $10^{\text {th }}$ day after which the chest tube was removed and the patient sent home. Presently the child is doing well and is on follow up.

\section{Discussion}

Eventration of the diaphragm is the condition where the muscle is permanently elevated, but retains its continuity and attachments to the costal margins. It was first described by Jean Louis Petit in 1774 during a postmortem examination [1]. Eventration is a rare, with a reported incidence of 1 in 1400 cases [2] and appears to be due to a congenital abnormality of the pleuroperitoneal membrane. Newborns with eventration may present with respiratory distress requiring mechanical ventilation,

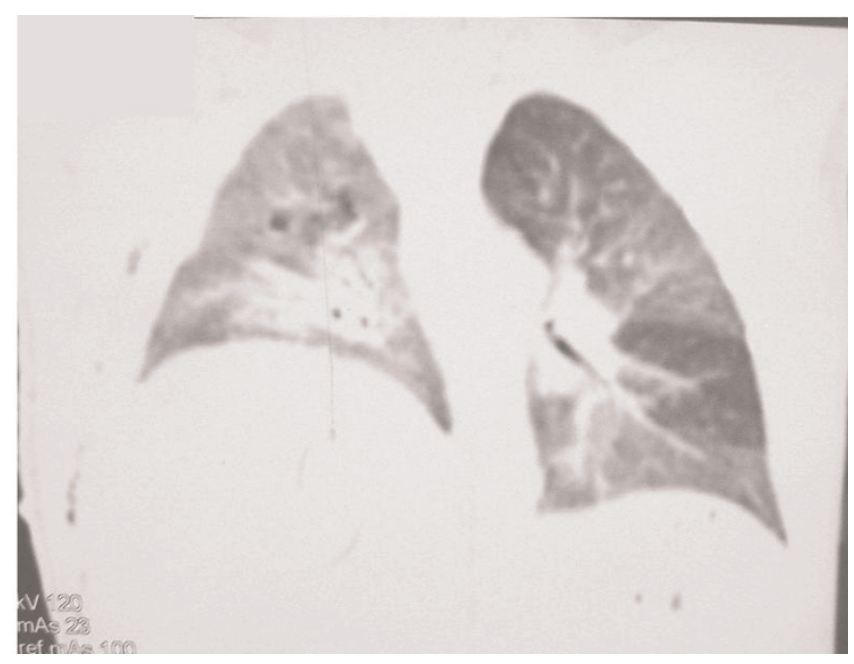

Figure 2. CT scan showing smooth outline elevated right hemidiaphragm. 
however it may remain asymptomatic and often requires no treatment. This condition may be confused with TDR in the trauma patient. Early differentiation and recognition of TDR is critical, as a delay in diagnosis is implicated in increased morbidity and mortality. A high index of suspicion, good past history and past and present imaging should aid in early and definitive diagnosis.

Diaphragmatic rupture is most commonly reported after trauma, either penetrating or blunt where the incidence is reported up to 6\% [3]. Diaphragmatic rupture is left-sided in 70 to 90 percent of cases [4]. Right-sided tears are eight times less common than left-sided tears [5]. Blunt trauma secondary to a motor vehicle accident is the most common cause of closed rupture of the hemidiaphragm, here a massive force is applied to the upper abdomen or the lower chest, resulting in sudden upward compression [4]. The sudden increase in intra-abdominal pressure relative to the intrathoracic pressure results in a pressure gradient across the diaphragm. Even a violent cough has been reported to cause TDR.

Most TDR are longer than $10 \mathrm{~cm}$ and occur in the posterolateral aspect of the hemidiaphragm; this site is structurally weak because of its origin from the pleuroperitoneal membrane. The size of the defect as well as the size and physical characteristics of the abdominal viscera adjacent to the defect, determine whether visceral herniation will occur. While left-sided lacerations result in large herniation of abdominal contents into the left hemithorax, right-sided tears more frequently are not accompanied by herniated viscera, because of the protective effect of the liver [6].

If the diagnosis of TDR is missed, the mortality and morbidity may rise upto $50 \%$ due to visceral herniation and strangulation. Unfortunately diagnostic modalities are insufficient. Although chest radiography is abnormal in $85 \%$, yet it is insensitive in depicting diaphragmatic rupture ( $46 \%$ sensitivity for left-sided ruptures and only $17 \%$ for right-sides ruptures [7]). On chest radiography signs are often masked by associated plural effusion, atelecteasis, pulmonary contusion or non-specific diaphragmatic elevation. For these nondiagnostic cases further evaluation is warranted. Diagnostic peritoneal lavage is un-reliable in detecting diaphragmatic injuries $[8,9]$, though occasionally lavage fluid may exit through the chest tube and establish the diagnosis [9]. In blunt trauma, though CT is the investigation of choice with sensitivity and specificity of $61-71 \%$ and $87-100 \%$, respectively in the diagnosis of diaphragmatic rupture [10]. Its main role is to rule out the other associated injuries, but it rarely allows identification of an isolated diaphragmatic rupture [11]. About half of the diaphragmatic disruptions are diagnosed for the first time at laparotomy or thoracotomy done for concomitant injuries $[8,9]$ as was in our case. In diagnosing isolated case of right-sided diaphragmatic rupture other investigations including liver scintigraphy [12], intra-peritoneal instillation of technetium [13] and celiac arteriography have been suggested as being of value. Where other measures fail laparoscopy should be considered to rule out diaphragmatic injury [14].

We highlight the importance of a high degree of suspicion for diaphragmatic injury considering even a laparotomy when imaging is unable to convincingly rule out such an injury. Past history or documentation of eventration should not preclude the diagnosis of TDR and these patients should receive a comprehensive work up to avoid the catastrophic risks of missing a TDR.

\section{Conclusion}

It is not uncommon for a practising surgeon to be misled by unusual history and false sense of security given by even high yield radiological gadgetry. It is only a surgeon being diaphragm conscious that an isolated diaphragmatic rupture is picked up even with the bizarre clinical presentation, from being completely asymptomatic to unexplained shock. Because of the great risk if the rupture is not corrected, a careful imaging assessment or laparoscopy should be obtained before discharge in any acutely injured patient who does not undergo surgical exploration.

\section{Abbreviations}

$\mathrm{CT}$, computed tomography; MVA, motor vehicle accident; TDR, traumatic diaphragmatic rupture.

\section{Consent}

Written informed consent was obtained from the parents of patient for publication of this case report and accompanying image. A copy of the written consent is available for review by the Editor-in-Chief of this journal.

\section{Competing interests}

The authors declare that they have no competing interests.

\section{Authors' contributions}

RAL, MLS, MW, SR, AGA, FR, MAB, AMD, GNL, SSi made substantial contributions to conception and design, acquisition of data and revising it. IM, SSh, MLS, FR, MLW contributed significantly in acquisition of data and drafting the manuscript.

\section{References}

I. Shah-Mirany J, Schmitz GL, Watson RR: Eventration of the diaphragm. Arch Surg 1968, 96:844-850.

2. McNamara Jj, Paulson DL, Urschel HC, Razzuk MA: Eventration of the diaphragm. Surgery 1968, 64:1013-1021.

3. Ward RE, Flynn TC, Clark WP: Diaphragmatic disruption secondary to blunt abdominal trauma. J Trauma 1981, 21:35-38. 
4. Dietrich P, Alsofrom G: The diaphragm. In Radiology: diagnosis,

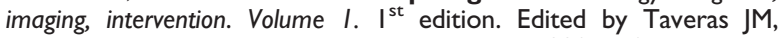
Ferrucci JT, Elliott LP. Philadelphia: Lippincott; 1990: I- I0.

5. Pailero PC, Trastek VF, Tayne WS: Oesophagus and Diaphragmatic hernia. In Principles of surgery. $5^{\text {th }}$ edition. Edited by Schwartz SI, Shires GT, Spencer FC. New York: McGraw-Hill; 1989:1 129-1 I 32.

6. Harris $\mathrm{JH} \mathrm{Jr}$, Harris $\mathrm{WH}$ : Chest. In The radiology of emergency medicine. $24^{\text {th }}$ edition. Edited by Harris JH Jr, Harris WH. Baltimore: Williams \& Wilkins; | 98।:422-427.

7. Gelman R, Mirvis SE, Gens D: Diaphragmatic rupture due to blunt trauma: sensitivity of plain chest radiographs. AJR I99I, 156:5I-57.

8. Beal L, McKennan M: Blunt diaphragm rupture. Arch Surg 1988, I 23:828.

9. Cox EF, Siegel JH: Blunt trauma to the abdomen. In Trauma: Emergency Surgery and Critical Care. Volume 107. Edited by Seigel JH. New York: Churchill Livingstone; 1987:883-910.

10. Killeen KL, Mirvis SE, Shanmuganathan K: Helical CT of diaphragmatic rupture caused by blunt trauma. AJR 1993, I73:16111616.

II. Sola JE, Mattei P, Pegoli W Jr, Paidas CN: Rupture of right diaphragm following blunt trauma in an infant. A case report. J Trauma 1994, 36:417.

12. Blumenthal DH, Raghu G, Rudd TG, Herman CM: Diagnosis of right hemidiaphragmatic rupture by liver scintigraphy. J Trauma 1984, 24:536.

13. Halldorsson A, Esser MJ, Rappaport W, Valente J, Hunter G, Mclntyre K: A new method of diagnosing diaphragmatic injury using intraperitoneal technetium. J Trauma 1992, 33:140.

14. Adamthwaite DN: Traumatic diaphragmatic hernia: a new indication for laparoscopy. $\mathrm{Br}$ ] Surg 1984, 7 I:3 I5.

\section{Do you have a case to share?}

Submit your case report today

- Rapid peer review

- Fast publication

- PubMed indexing

- Inclusion in Cases Database

Any patient, any case, can teach us something

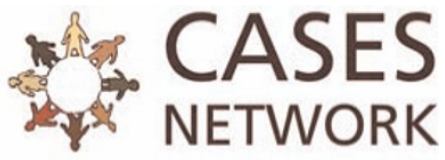

www.casesnetwork.com 